\title{
EL MITO FALLIDO SACROMONTANO Y SU \\ PERDURABILIDAD LOCAL A LA LUZ DEL MOZARABISMO MAURÓFOBO DE F. J. SIMONET
}

\author{
José ANTONIO GoNZÁLEZ AlCANTUD \\ Universidad de Granada \\ y Centro de Investigaciones Etnológicas «Ángel Ganivet»
}

Los mitos prosperan o no prosperan. En el primer supuesto, permanecen en el tiempo y se universalizan; en el segundo, devienen mitos fallidos. Casos más extraños son los mitos fallidos que, no obstante su inicial fracaso, enraízan localmente y se sostienen con tozudez gracias al concurso de la población nativa y sobre todo de sus élites. El complejo mítico-ritual del Sacromonte granadino, que incluye en principio todo lo concerniente a los fenómenos maravillosos asociados a la rábita del Aceituno, luego ermita de San Miguel, en lo más alto del monte, a la conversión de éste en una gitanería troglodítica y a la erección en el mismo de una abadía donde se rinde culto a los mártires preislámicos, constituye un conjunto integrado y conformado por el hecho fallido principal: el gran laboratorio mítico-ritual derivado de los Libros Plúmbeos, puesto en marcha por el arzobispo Pedro de Castro. En la formación del mito tuvieron parte principalísima moriscos conversos, como Alonso del Castillo; esto es cosa sabida y probada, y en torno a este hecho giran casi todas las explicaciones historiográficas. Empero, como señaló en su momento Darío Cabanelas, en el surgimiento del mito mismo quizás pudo más el interés por exaltar a Granada y sus excelencias frente a otras ciudades de España ${ }^{1}$, con lo cual la tesis local prevalece sobre cualquier otra en la lógica de la formación del mito. De otra parte, los estudios críticos de Manuel Barrios Aguilera han demostrado con claridad la naturaleza intencional y la orientación de los «inventores de la tradición» sacromontana más allá del momento inicial, los cuales serían los encargados de preservar y velar por el «espíritu del lugar» ${ }^{2}$, verdadera clave de la bóveda mítico-ritual sacromontana.

\footnotetext{
${ }^{1}$ Cabanelas Rodríguez, D., El morisco granadino Alonso del Castillo, Granada, 1991, 287.

2 Barrios Aguilera, M., «Granada en escorzo. Luis Francisco de Viana y la historio-

Al-Qanțara XXIV, 2 (2003) 547-574
} 
El mito, según Lévi-Strauss, posee una «tendencia y proyectiva», y «jamás refleja un estado o momento». Los mitos no son fijos y están en movimiento, en definitiva. Lévi-Strauss dice que «la ciencia de los mitos es una anaclástica (...), que admite en su definición tanto el estudio de los rayos reflejados como el de los refractados». Señala el antropólogo que a diferencia de la reflexión filosófica - y en buena medida también histórica, según nuestro criterio-, que remite al discurso de los orígenes, «la divergencia de las sucesiones y también de los temas es un atributo del pensamiento mítico» ${ }^{3}$. Siguiendo este método de fondo, a nosotros, en tanto que antropólogos, nos interesa la naturaleza estructural del mito sacromontano. Y su componente $f a-$ llido, ya que éste nos revela mucho más sobre los sujetos colectivos que el mito mismo.

Otro problema antropológico básico e infrecuentemente contestado, probablemente porque los antropólogos no se hayan ocupado del mito que encarna el Sacromonte granadino, es el porqué de esta permanencia, el porqué de esa persistencia, a pesar de las desautorizaciones de la Iglesia romana. El mito sacromontano tiene que poseer un poderoso anclaje local, y por ende en los medios eclesiásticos granadinos, para haber conseguido permanecer en el tiempo. Lo cual llevó a la Iglesia a reconocerlo de interés local y salvar de esta manera el proyecto. Aún hoy día el estamento eclesial sigue sosteniendo parte del mito de manera más o menos sutil y soterrada ${ }^{4}$. Nos queda, sin embargo, encontrar las razones lógicas para esa persistencia, dado que ni siquiera San Cecilio fue un santo conocido por su milagrería, ni la abadía sacromontana fue ni es un lugar de culto frecuentado. Francisco Javier Simonet, catedrático de lengua árabe de la Universidad granadina en la segunda mitad del siglo XIX, nos sirve de recurso y excusa para explicar esa permanencia temporal, tozuda donde las haya.

grafia del Sacromonte», Demófilo, n. ${ }^{\circ} 35$ (2000), 45-80. Y estudio introductorio a: Heredia Barnuevo, D. N. de, Místico ramillete. Vida de Don Pedro de Castro, fundador del Sacromonte. Granada, 1998.

${ }^{3}$ Lévi-Strauss, C., Mitológicas I. Lo crudo y lo cocido. México, 1968, 15.

${ }^{4}$ Barrios Aguilera, M., «El bucle metahistórico. Los libros plúmbeos de Granada, realidad histórica y mito», Fundamentos de Antropología, 10-11 (2001), 321-333. 
Simonet ${ }^{5}$ era un sabio conocedor de la lengua árabe, con seguridad uno de los mejores arabistas de su tiempo, lo que no le impidió ser un tremendo reaccionario, situado ideológicamente a la derecha del carlismo. Natural de Málaga, se había abierto camino en Madrid, gracias al círculo del arabista y literato costumbrista Serafín Estébanez Calderón, también nativo de Málaga. Su fobia hacia la cultura árabe, simultánea con su atracción por la lengua, lo ha convertido en un ejemplo paradójico del dispositivo interno de algunos orientalistas españoles, y en particular de la «escuela granadina», moviéndose entre la atracción y el rechazo, cuando no repulsión, hacia su objeto de estudio. Consagró, bien es sabido, la mayor parte de su obra a demostrar la importancia que el elemento mozárabe e indígena había tenido en la gestación de la cultura hispanoárabe. Cabe explicar su dispositivo interior en términos psicoculturales, recurriendo para ello a ciertas aportaciones del psicoanálisis. Se trata de explicar el surgimiento de una fobia, que acaba deviniendo xenófoba desde el punto de vista cultural, y sólo los psicoanalistas se han preocupado por aquella forma de distorsión psíquica ${ }^{6}$. En nuestra opinión la categoría «ideología» aplicada a Simonet y su círculo resulta insuficiente para explicar la magnitud del desprecio que este autor tenía hacia la cultura árabe, ya que en muchas ocasiones presenta manifestaciones típicas de los delirios fóbicos por su fijación obsesiva. Sin embargo, en las fobias, según $\mathrm{S}$. Freud, el estado emotivo está presidido por la angustia, que a

5 Debe disculpar el lector este largo introito sobre la figura de Francisco Javier Simonet, ya que sin la misma no se lograría la comprensión del nudo mítico desarrollado por este autor, a pesar de que algunos de los datos sobre su vida, y sobre todo de su ideología, le sean sobradamente conocidos.

6 Si la conexión entre antropología y psicoanálisis ha sido explorada con cierta fruición en la década de los setenta, la de la historia y el psicoanálisis lo ha sido sólo en una medida testimonial. Únicamente algún autor aislado, como Michel de Certeau, se ha preocupado de buscar las conexiones entre el acontecimiento histórico y la interpretación psicoanalítica. Certeau defendió la existencia de dos estrategias del tiempo, la psicoanalítica y la histórica, como parte de un mismo proceso: «La historia es "caníbal", y la memoria deviene el campo cerrado donde se oponen dos operaciones contrarias: el olvido, que no es una pasividad, una pérdida, sino una acción contra el pasado; la traza mnésica, que es el retorno de lo olvidado». Sigue reflexionando Certeau que «la historiografia se desarrolla al contrario en función de una ruptura entre el pasado y el presente». Los mecanismos del psicoanálisis y de la historia serían, pues, «dos maneras diferentes de distribuir el espacio de la memoria», la una centrada en la continuidad y la otra en la ruptura. Para el caso que aquí nos ocupa parece absolutamente adecuada la apertura de la historia hacia el psicoanálisis (Michel de Certeau, Histoire et psychanalyse entre science et fiction, París: Gallimard, 2002, 85-86). 
diferencia de la obsesiones no procede del «recuerdo» ${ }^{7}$. El origen de la fobia simonetiana debe proceder, por tanto, de un momento coetáneo al autor, y no tanto de alusiones históricas al mundo islámico andaluz. Esa presencia es la leyenda negra y el mito sacromontano.

Sabido es que Simonet se nutría ideológicamente de periódicos integristas de la órbita carlista. La identidad de fines que establecía entre el liberalismo contemporáneo y el islamismo histórico le hizo vivir con pasión de militante político su condición de arabista. Resumiendo este estado de ánimo, su discípulo Antonio Almagro nos dice que «fue, por lo tanto, no sólo integrista sino una de las piedras angulares del integrismo» ${ }^{8}$. Simonet aprovecha cualquier ocasión para sostener sus criterios integristas sobre fundamentos intencionalmente irracionales, otorgando un papel relevante a la presencia de signos de origen divino en la Historia. Por ejemplo cuando se celebra en 1889 el XIII centenario del Concilio de Toledo, enfrenta esta celebración a la del centenario de la Revolución Francesa, ocurrida dos años antes, revolución donde para él se esconde la mano del maligno. Incluso tiene detalles chuscos y propios de un crédulo cualquiera, como la siguiente nota a pie de página: «El 17 de junio de 1689 el Corazón de Jesús manifestó a la beata Margarita Alacoque el deseo que tenía de establecer su reinado social en las naciones. Esta invitación no halló eco en el gobierno francés, y cabalmente en el mismo día de 1789 estalló la Revolución Francesa» ${ }^{9}$. Puede en él la creencia sobre cualquier otro criterio.

No obstante, cuando Simonet llega a Granada su discurso se acerca a unas posiciones moderadas y hasta tímidamente panarabistas, que explicitó en sus contribuciones al diario «La América» en los años de la guerra de Tetuán ${ }^{10}$, y que finalmente formuló de forma académica

${ }^{7}$ Freud, S., «Obsesiones y fobias. Su mecanismo psíquico y su etiología», Obras completas, Buenos Aires, 1993, vol. 2, 178-182.

8 Sobre la emergencia de la «fobia cultural» como concepto antropológico que va más allá de la mera ideología, y por tanto de lo consciente, véase: González Alcantud, J. A., Lo moro. Las lógicas de la derrota y la formación del estereotipo islámico, Barcelona, 2002, y González Alcantud, J. A., «Pasión fría y objeto fóbico. El círculo orientalista Estébanez, Cánovas y Simonet». Lisón Tolosana, C. (ed.), Antropología: horizontes emotivos, Granada, 2003.

9 Simonet, F. J., «Prólogo», El concilio de Toledo, base de la nacionalidad y civilización española, Madrid, 1891, VIII.

${ }^{10}$ López García, B., «F. J. Simonet ante el colonialismo, 1859-1863. Unos artículos en "La América"», Cuadernos de Historia del Islam, n. 3 (1971), 159-178. 
en su discurso de recepción como catedrático de la Universidad granadina en 1862. En esta intervención académica sostuvo: «Los musulmanes han mirado siempre con gran respeto las tradiciones religiosas y los lugares sagrados para israelitas y cristianos, como también los recuerdos venerables de los antiguos legisladores y profetas hebreos, de Jesucristo y de su Santísima Madre (...) no mencionándolos jamás sin acompañar a sus nombres con una fórmula de reverencia (...) De esta tolerancia nace el que los historiadores árabes usen ordinariamente de bastante imparcialidad en lo tocante a los sucesos de nuestros cristianos, cuyos usos, leyes y creencias respetaron generalmente; sin que el fanatismo religioso les haya movido a adulterar la verdad de sus relaciones» ${ }^{11}$. Al final de su discurso, Simonet insiste en la importancia del conocimiento del árabe, evitando que sean los extranjeros los que por la proverbial desidia española ocupen el espacio del orientalismo, para acabar con la afirmación que sigue: «Especialmente en esta ciudad de Granada yo me lisonjeo que este bello y fructuoso estudio ha de tener cada día mayor número de adeptos y ha de brillar más y más la escuela árabe que en ella florece». Profesión de fe en el deseo de esta ciudad de ocupar un lugar central en los estudios orientalistas que ya comenzaba a abrirse camino como proyecto.

No aparece, por consiguiente, en esta fecha, ninguna alusión ultracatólica en el discurso de Simonet, diferenciándose de la posición que sólo un año después comienza a adoptar y que seguramente responde a un profundo cambio del estado de ánimo del arabista, después de su estadía granadina. Como se doctoraría después de ser catedrático, ya que accedió a este puesto con una autorización especial dados sus amplios conocimientos de la lengua árabe, pudo afirmar en el discurso de investidura como doctor al año siguiente de hacer las afirmaciones anteriores: « $\mathrm{El}$ amor de la verdad y el respeto debido a la civilización española, eminentemente cristiana, nos obligan á rechazar las temerarias afirmaciones de un orientalista moderno que exagera extraordinariamente la influencia y la supremacía literaria de los árabes en la Edad Media. Nosotros reconocemos con Mr. Sedillot que los árabes de España estaban realmente en el siglo XI a la cabeza de las naciones cultas, pero sólo en lo tocante a la industria de las ciencias y artes de-

11 Simonet, F. J., Discursos leidos ante el claustro de la Universidad literaria de Granada, en el acto solemne de recepción del Licenciado don F. J. S. como catedrático numerario de lengua árabe (...) el día 15 de septiembre de 1862, Granada, 1867. 
terminadas, y de ningún modo en las demás ramas de la civilización fecundadas por la savia inmortal del cristianismo (...) Para ensalzar la cultura mahometana no rebajemos la propia ni sublimemos el Islam á costa del cristianismo» ${ }^{12}$. Se ve cómo Simonet en un breve período de tiempo y coincidiendo con su traslado a Granada, comienza a cambiar su percepción de la cultura árabe, pasando de una inicial admiración paralela al orientalismo, en la que parece no interferir excesivamente la guerra de Tetuán, a un rechazo de su importancia «espiritual» y de su relativa superioridad «material», hasta arribar a sus conocidas posiciones de rechazo a todo lo que significase arabidad. En aquel mismo tiempo, el granadino Pedro Antonio de Alarcón, al calor de la opinión pública favorable a la guerra patriótica, componía su Diario de un testigo de la Guerra de África (1860), que constituye un hito ejemplificante de la compulsión diádica entre atracción y rechazo del moro magrebí. Esta pulsión, siendo muy fuerte en Alarcón, que vive bajo el signo de una contradicción que resuelve en la afirmación del sí mismo romántico con todas sus aristas poliédricas, no encuentra eco en Simonet que acaba abriendo un foso dicotómico entre su inicial y timidísimo orientalismo y la fobia cultural ulterior ${ }^{13}$.

La obra de Simonet lleva a cabo un feroz ataque al orientalismo europeo, movimiento al que atribuye el origen de la exaltación e idealización arabista, trayecto en el que paradójicamente le aporta su concurso indirecto R. Dozy, conceptuado por él como «protestante y racionalista». $\mathrm{Y}$ lo hace en los siguientes y contundentes términos, pronunciados en la inauguración del curso 1876-77 en la Universidad de Granada: «Así, pues, el mal de que nos quejamos, este mal que se avecina a la muerte, no se debe a otra cosa que al abandono de la verdad, a los golpes que ha sufrido el catolicismo, único elemento civilizador de Europa, y en particular de nuestra patria (...) A este desmayo en la fe, a esta grande apostasía de las misiones católicas, inficionada por el protestantismo inglés y germánico, se deben todos los golpes

12 Simonet, F. J., Discurso leído ante el claustro de la Universidad Central por don F. J. S. en el solemne acto de recibir la investidura de Doctor en Filosofia y Letras, Granada, 1867.

13 Véase al respecto del estado de la opinión pública de la época: Lécuyer, M. C. \& Serrano, C., La guerre d'Afrique et ses répercussions en Espagne, 1859-1904. París, 1976. Y en relación a Alarcón: González Alcantud, J. A., «La poética de la conquista en la obra orientalista de Pedro Antonio de Alarcón», VV.AA., Pedro Antonio de Alarcón y la guerra de África, Granada, 2003, 9-24. 
que de un siglo acá vienen sufriendo el arte y la literatura, la ciencia y la enseñanza» ${ }^{14}$. Es evidente que para Simonet la leyenda negra, como mito conspiratorio, es el factor operativo más importante que define su actividad política e ideológica. Para él uno de los problemas más relevantes serán los derivados de la precitada leyenda negra creada, a su juicio, intencionalmente: «Más terribles y fuertes son á primera vista los cargos que en diferentes épocas, y sobre todo, en la segunda mitad del siglo pasado, en la efervescencia de la sofisteria y de la incredulidad, hicieron a nuestra patria varios escritores extranjeros, entre ellos el historiador inglés Roberson y el francés Raynal, pretendiendo en suma que los españoles maltrataron y casi destruyeron á los americanos con su crueldad, codicia y despotismo»" ${ }^{15}$. Simonet se adelanta en esto a la opinión de Julián Juderías ${ }^{16}$, quien, años después, sostendría que «la existencia de la leyenda negra se debe principalmente a que la Historia de España no la hemos escrito nosotros, sino los extranjeros» ${ }^{17}$.

La «violencia» de la producción de Simonet se observa además en sus obras aparentemente más asépticas, como fueron Crestomatía arábigo-española y Glosario de voces ibéricas y latinas, publicadas

14 Simonet, F. J., Discurso leído ante la Universidad Literaria de Granada en la solemne apertura del Curso Académico de 1876-77, manuscrito, Biblioteca Universitaria de Granada.

15 Simonet, «Prólogo», Ibáñez y García, L. de, Historia de las Islas Marianas con su derrotero, y las Carolinas y Palaos, desde el descubrimiento por Magallanes, Granada, 1886, VI.

16 Juderías, J., La leyenda negra, El Escorial, 1987 (1914), 318.

17 Guiándose por este criterio defiende a toda costa la bondad del sistema colonial español, uno de los elementos de la historia hispana más devaluados, en términos que eran muy frecuentes en la época en los medios españoles: «La maravillosa superioridad de nuestras colonias se debe á la excelencia del fin que en ellas se propusieron nuestros egregios mayores y al espíritu que los animó en tales intentos; que no fue, como en otras naciones europeas, lucrar y enriquecerse con el despojo de los pueblos sometidos y las especulaciones comerciales, sino ganar almas para Jesucristo y dilatar su bendito reino» (Simonet, Fr. J., «Prólogo», Ibáñez y García, Luis de, Historia de las Islas Marianas, IV). Frente a la colonización europea conducida por el interés comercial, alza Simonet la española, orientada por la religión y el idealismo. Con motivo del descubrimiento de América y del II Congreso Católico nacional, celebrados ambos en octubre de 1892 en Sevilla, el discurso de Simonet pivota de nuevo sobre sus particulares obsesiones. De las tierras de América señala "que afortunadamente nunca fueron conocidas de los Árabes» (Simonet, Fr. J., Misión civilizadora de la Iglesia Católica y de la nación española en el descubrimiento del Nuevo Mundo, Granada, 1893, 19. Vide igualmente: Simonet, F. J., Los conocimientos geográficos de los autores árabes con relación al descubrimiento del Nuevo Mundo, Archivo Universitario de Granada, caja 2-17 (6)). Su providencialismo extremo lo traslada, en virtud de la leyenda negra, a tierras americanas. 
respectivamente en 1881 y 1888 . Al escribir, junto con el prefecto apostólico de la Misión franciscana en Marruecos, José de Lerchundi ${ }^{18}$, una obra de divulgación del árabe, como es la «Crestomatía» no persigue otra finalidad que «proporcionar á las escuelas de nuestra patria un libro especial (....) [que] pueda facilitar la enseñanza de tan difícil idioma, avivar las afición de nuestros compatriotas a favor de un estudio que pueda cooperar sobremanera a la ilustración de la historia nacional y la propagación de nuestra fe y civilización católica por vastas regiones, y por último, el contribuir, en cuanto lo permitan las dimensiones del presente libro, á inspirar la idea más acertada de la literatura arábiga en sus varias relaciones con la historia y nacionalidad ibérica» ${ }^{19}$. No admite la más mínima posibilidad de que el aprendizaje del árabe suponga una fase del reconocimiento del pasado islámico, sino que su importancia proviene sobre todo de la necesidad de evangelizar la España Transfretana, es decir Marruecos. En esa línea lo encontramos insistiendo en la necesidad de apoyar a la Misión franciscana de Tánger ante el primer Congreso español de africanistas, celebrado en Granada en octubre de 1892, y en cuyas sesiones, que presidía su discípulo Almagro Cárdenas, debió intervenir ${ }^{20}$. En el Glosario, aparecido siete años después, Simonet sostiene que aunque Dozy ha rectificado sus iniciales posiciones empáticas con la cultura árabo-andalusí, él cree que la influencia del elemento indígena en los ocupantes fue mayor de la que le confiere el historiador holandés, llegando a hablar de persistencia de un «un gran miajón de población ro-

\footnotetext{
${ }^{18}$ La amistad del Padre Lerchundi y Simonet proviene sobre todo de la estancia del primero en Granada, momento en el que escribieron conjuntamente la Crestomatía. Lerchundi se preocupó especialmente por el «árabe vulgar», aspecto sobre el que publicó un tratado en 1872 (Rudimentos del árabe vulgar, Madrid, 1999. Ed. facsímil con estudio preliminar de Ramón Lourido Díaz), mientras que el discípulo de Simonet, Almagro Cárdenas haría otro en 1882, diez años después (Almagro Cárdenas, A., Compendio gramatical y léxico del árabe vulgar de Marruecos, formado con los datos adquiridos en la expedición que al Imperio Marroqui hizo el Dr. Antonio Almagro Cárdenas, en cumplimiento de la Real Orden de 19 de julio de 1881, manuscrito conservado en la Escuela de Estudios Árabes de Granada). La preocupación por el «árabe vulgar» va de Lerchundi a Almagro Cárdenas, en un continuum marcado por la utilidad misional simonetiana.

19 Simonet, F. J. \& Lerchundi, J., Crestomatía Arábigo-Española o colección de fragmentos históricos geográficos y literarios... seguida de su vocabulario, Granada, $1881, \mathrm{VI}$.

20 VV.AA., Actas y memorias del Primer Congreso Español de Africanistas, Granada, 1894.
} 
mana y gótica», en expresión de su maestro Estébanez Calderón ${ }^{21}$. De esta manera resume y justifica su afición a la lengua arábiga, a la búsqueda de herencias culturales preislámicas, y por razones de eficacia misional.

Pero para nuestra finalidad, es decir, mostrar la íntima relación entre la emergencia de la maurofobia simonetiana y la omnipresencia del mito sacromontano como hueco del sentido surgido a raíz de su traslado a Granada, lo más interesante es la confesión que hace Simonet, dejando de lado cualquier veleidad suya de simpatía juvenil con el mundo islámico: «Ni se suponga por esto que yo miro como cosa liviana y baladí el estudio de una lengua y una literatura á que he consagrado gran parte de mi vida, y á la que en otro tiempo he tributado loores excesivos, inspirados por la admiración juvenil» ${ }^{22}$. No podemos olvidar lo que debe esta fobia cultural fundada en la leyenda negra a la presencia cerca del círculo frecuentado por Simonet, y en más en concreto de Estébanez Calderón, su maestro en la lengua árabe, de una figura como Luis Usoz del Río, quien se convertiría en protestante y propagandista de esta religión en España, encarnando así para aquel círculo el ejemplo vivo de la anti-España ${ }^{23}$. De esta manera queda justificada la acertada opinión de Manuela Marín que sostiene que el arabismo en España es «un asunto de familia» ${ }^{24}$. También debe tenerse presente el ataque soterrado o abierto que su obra sostiene en contra de los arabistas afrancesados o liberales, como son José Antonio Conde o Pascual Gayangos, a los cuales no tiene empacho en considerar de hecho parte de una conspiración antiespañola ${ }^{25}$.

La estructura mental que guía a Simonet, como una hipérbole de la maurofobia que existió en algunos círculos orientalistas españoles, y sobre todo en el granadino, donde este sentimiento era prepon-

21 Simonet, F. J., Glosario de voces ibéricas y latinas usadas entre los mozárabes. Madrid, 1882, LXXX.

${ }^{22}$ Simonet, F. J., El Cardenal Ximénez de Cisneros y los manuscritos arábigo-granadinos. Granada, $1885,34$.

${ }_{23}$ Vide entre la escasa bibliografia al respecto: Cobo, E., Luis Usoz y Río. Antología, Madrid, 1986.

${ }^{24}$ Marín, M., «Arabistas en España: un asunto de familia», Al-Qanțara, XIII (1992), 378-393.

${ }^{25}$ Uno de los pocos historiadores del arabismo español que ha puesto en relación íntima las ideologías políticas y la producción arabista es el siempre recomendable Monroe, J. T., Islam and the Arabs in Spanish Scholarship. Sixteenth Century yo the Present. Leiden, 1970, 49-99. 
derante, difiere notablemente de las raíces históricas del orientalismo francés, el más cercano y el más potente en relación al español, con el cual mantiene fuertes vínculos. Aunque la visión última que pudiésemos tener de un Silvestre de Sacy, maestro de Gayangos, fuese la que nos da Edward Said, es decir de alguien que «canoniza el Oriente; [y] engendra un canon de objetos textuales que pasa de una generación de estudiantes a otra» ${ }^{26}$, el orientalismo francés siempre sería de menor combatividad ideológica, y por supuesto sería más inocente. Si enfrentamos a Simonet con el racionalismo jansenista de Sacy, uno de cuyos ancestros había polemizado con Pascal, observamos que no existe el mismo fuego en uno y otro orientalismo. Al analizar la figura de Renan, un orientalista grandemente ideológico, nutrido por un espíritu patriótico y católico similar al de Simonet, observamos diferencias notables igualmente ${ }^{27}$. Las condiciones culturales y políticas para la emergencia de las fobias parecen diferentes, y exigen estudios comparativos ulteriores que permitan alumbrar las raíces nacionales de la confrontación intelectual con la alteridad islámica.

${ }^{26}$ Said, E., L'Orientalisme. L'Orient créé par l'Occident, París, 1980, 153.

27 Renan en el «Averroès et l'averroïsme», publicado en 1852, que constituyó su tesis doctoral, arremete también contra la cultura islámica. Hasta este punto se comporta igual que Simonet, y a partir de aquí comienzan sus diferencias. Según Renan: «Incapaz de transformarse y de admitir ningún elemento de la vida civil y profana, el islamismo arranca de su seno todo germen de cultura racional. Esta tendencia fatal fue combatida, mientras que la hegemonía del islamismo quedó en manos de los árabes, raza fina y tan espiritual, o de los persas, raza muy dada a la especulación; pero ella reina sin contrapeso desde que los bárbaros (turcos, beréberes, etc.) tomaron la dirección del Islam. El mundo musulmán entra desde entonces en este período de ignorante brutalidad de donde no ha salido más que para caer en la mayor agonía en donde se debate bajo nuestros ojos» (Ernest Renan, «Averroès et l'averroïsme», Oeuvres Complètes, Tome III, París, 1949, ed. H. Psichari, 13). Renan ensalza a los árabes, y señala a las adherencias «bárbaras» como responsables de la decadencia musulmana. Aquí podemos hallar en parte, justificada la aversión para los orientalistas, por ejemplo, hacia la figura de Averroes. Su naturaleza ambigua en el plano religioso ha hecho que tanto católicos como musulmanes hayan evitado su encuentro en muchos momentos, hasta el punto que D. Urvoy sigue hablando de una figura "mítica y desconocida» (Urvoy, D., Averroès. Les ambitions d'un intellectuel musulman, París, Flammarion, 1998). Está claro que a los patriotismos francés y español de origen católico les afectaba sobremanera la presencia fantasmagórica del Islam. No obstante, el mayor combate del pensamiento reaccionario español, tal como lo demostró en su tiempo Javier Herrero, era la «filosofía», es decir, el razonamiento, y ello disgregaba numerosas posibilidades analíticas, al contrario que en el mundo francés (Herrero, J., Los orígenes del pensamiento reaccionario español, Madrid, 1971, 395-400). 
Del orientalismo estetizante que idealizaba el pasado árabe de Granada, ni siquiera el jansenista Sacy ni el católico Renan escapan. Como siempre Simonet ataca los orientalismos hiperbólicos, que en el fondo encarnan investigadores como Sacy y Renan: «Estas y otras exageraciones tienen su raíz en el espíritu de cierta escuela moderna empeñada en realzar el mérito de los musulmanes para deprimir a los cristianos de los siglos medios, así libres como sometidos» ${ }^{28}$. En otro lugar escribe: «Conviene advertir previamente en la exagerada cultura de los moros de Granada, no es oro cuanto reluce y aparece a primera vista, sino en gran parte encarecimiento de poetas y novelistas, así de los arábigos, ciegos admiradores y apasionados de esta especie de paraíso terrenal, como de los españoles y europeos entusiasmados con las bellezas naturales del país y con la importancia de una conquista que vino a contemplar la restauración de nuestra patria» ${ }^{29}$. Esta capacidad de seducción de Granada se la adjudica a las cualidades naturales de su entorno físico y a «su pintoresca situación, así como también a labores y procedimientos agrícolas practicados desde remota edad y con mucha anterioridad a la invasión sarracénica y conservada por la raza indígena» ${ }^{30}$. Destaca asimismo lo que llama el «sensualismo mahometano», subrayando que «nada más sensorial y voluptuoso que la imagen del paraíso que, según el abad mozárabe Esperaindeo, no debería llamarse paraíso sino lupanar y lugar obscenísimo, y que según César Cantú, participa de lupanar y de figón». En la mejor tradición freudiana, es la mujer la que centra la obsesión fóbica, atribuyendo a las cristianas unos valores morales superiores que niega insistentemente a las musulmanas, a las que considera atadas a la lubricidad ${ }^{31}$. De esta manera Simonet nos descubre sin veladuras la naturaleza psicótica de algunos de sus complejos.

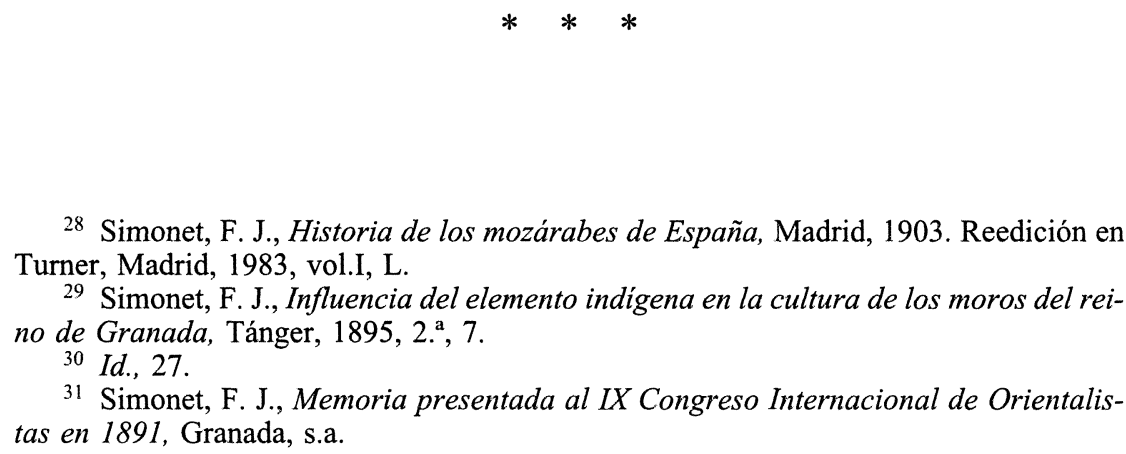

28 Simonet, F. J., Historia de los mozárabes de España, Madrid, 1903. Reedición en Turner, Madrid, 1983, vol.I, L.

${ }^{29}$ Simonet, F. J., Influencia del elemento indigena en la cultura de los moros del reino de Granada, Tánger, 1895, 2. ${ }^{\text {a }} 7$.

${ }^{30}$ Id., 27.

${ }^{31}$ Simonet, F. J., Memoria presentada al IX Congreso Internacional de Orientalistas en 1891, Granada, s.a. 
En todo sigue Simonet al padre Flórez, quien quiso darle un punto de racionalidad a la narración fundacional de la hispanidad católica, separándola de sus mixtificaciones más groseras. Si bien, cuando trata de tradiciones relacionadas con la piedad, piensa Flórez, la inicial actitud racional debe modificarse, puesto que «hay que admitirlas mientras no se demuestre con certeza que son erróneas»" ${ }^{32}$. Los mitos de fundación constituyen una fantasmática y una legitimidad sobre la ocupación territorial que trasciende los tiempos. Simonet es consciente de ello y establece una lucha políticamente violenta por demostrar, al igual que en otros ámbitos, la precedencia del cristianismo en el origen de la ciudad, intentando expurgar, como Flórez, lo más desacreditado de los cronicones para salvar el núcleo de la narración mítica. La primera polémica, que considera ajena a su especialidad, no obstante, es la de la ubicación de la antigua Granada: «Para concluir ya esta prolija controversia sobre la relación de los pueblos Iliberis y Granada, diré yo, en conformidad con las observaciones del distinguido anticuario granadino antes citado [Lafuente Alcántara], creo que la moderna Granada fue un suburbio de la antigua Iliberis, la cual, según los datos más seguros, estuvo donde hoy el Albaicín, extendiendo más en lo llano sus arrabales y fortalezas de Granata, Casthela y el castillo llamado en tiempo de los árabes Hisn Arroman. La Iliberis romana y Elbira árabe, con el transcurso y alteración de los tiempos, llegó a transformarse en Granada, conservándose el nombre de Elbira en Casthilia ú otro punto de aquellos contornos, en donde, como es sabido, estuvo bajo la dominación la residencia del guali y capital de la comarca». A pesar de sus retorcidos argumentos que pretenden demostrar que Granada es un calco cartográfico de Iliberis, Simonet concluye prudentemente: «Dispensen mis benévolos lectores que les haya entretenido tanto con esta curiosa pero interminable cuestión, la cual no presumo de manera alguna haber dejado resuelta, á pesar de tantos argumentos presentados en pro y en contra» ${ }^{33}$. Podemos asociar esta inicial prudencia de Simonet a la temprana fecha en la que escribe el libro Descripción del Reino de Granada bajo la dominación de los naseritas, es decir 1860, libro que le valió la cátedra de

${ }^{32}$ Mestre, A., Despotismo e Ilustración, Barcelona, 1976, 87.

33 Simonet, F. J., Descripción del Reino de Granada bajo la dominación de los naseritas, sacada de los autores árabes, y seguida del texto inédito de Mohammed Ebn Aljathib, Madrid, 1860, 40-41. 
Granada, y a su autoproclamada incompetencia en materia arqueológica.

Cuando llega a Granada, al ser nombrado catedrático de árabe de su Universidad, Simonet se enfrenta in situ a los mitos locales ${ }^{34}$. En primer lugar al mito por excelencia de la ciudad: el de fundación. Lógicamente, Simonet hubo de confrontar sus conocimientos y sus creencias con el mito sacromontano, aunque no dedicara ninguna obra o folleto expresamente al mismo. "Al cambiar de nombre, la antigua sede episcopal de San Cecilio cambió notablemente de fortuna, atravesando bajo las dinastías de los Ziritas y Nazaritas un largo período de ominoso yugo sarracénico y de grandeza material, hasta que rescatada por los ínclitos restauradores de la España católica, recobró con creces su importancia religiosa y civil, y reuniendo con los trofeos de la reconquista los recuerdos de sus altas glorias iliberritanas, enriqueció para siempre con su Granada los simbólicos blasones de su escudo nacional» ${ }^{35}$. Lugar central en la construcción del mito ocupan a lo largo de los siglos XVI-XVIII los Libros Plúmbeos del Sacromonte y las excavaciones albaicineras en la Alcazaba Qadima del presbítero Juan de Flores ${ }^{36}$. Todos ellos alcanzan su materialización en torno a las cuevas sacromontanas donde habrían sufrido martirio San Cecilio y sus compañeros, los Varones Apostólicos. Del santuario sacromontano dice por extenso Simonet: «Existe en las afueras de Granada un santuario venerable y famoso por más de un concepto, aunque obscurecido en sus legítimas glorias por la falsa piedad de hombres ilusos que adulteraron sus tradiciones, mezclando con memorias auténticas y hechos reales no pocas patrañas e imposturas. Este santuario es el Sacro Monte, erigido á principios del siglo XVII

\footnotetext{
${ }^{34}$ Granada es un ojo de huracán en su época, dado que en ella ha alcanzado una dimensión trágica el enfrentamiento entre las élites liberales e integristas, que había tenido como expresión pública la ejecución de Mariana de Pineda en 1831. En la Granada de Simonet se encontraba viviendo la hija de Pascual Gayangos, que estaba casada con un importante liberal, Juan Facundo Riaño, amigo del krausista Francisco Giner. La confrontación llegaba, pues, muy cerca de Simonet (Monroe, J. T., Islam and the Arabs, 81).

${ }_{35}$ Simonet, F. J., Cuadros históricos y descriptivos de Granada, Madrid, 1896, 13.

36 Respecto a las infructuosas excavaciones del presente véase: Malpica Cuello, A., Granada islámica. Mitos y realidades, Granada, 2000; Malpica Cuello, A., «Acerca de la ciudad de Granada y sus orígenes», Barrios Rozúa, J. M. (ed.), El Albaicín. Paraíso cerrado, conflicto urbano, Granada, 2003, 9-19. Sobre las excavaciones de Juan de Flores véase el siempre útil libro de Sotomayor, M., Cultura y picaresca en la Granada de la Ilustración. Don Juan de Flores y Oddouz, Universidad de Granada, 1988.
} 
por un ilustre Arzobispo de Granada, y roca firme que ha resistido hasta ahora el oleaje revolucionario de nuestro siglo» ${ }^{37}$. Sobre estas sagradas cuevas, y la verosimilitud de que en ellas hubiesen sufrido martirio los Varones Apostólicos arguye: «Contra esta creencia se han levantado en nuestro siglo graves polémicas (...), y cuyas razones nos parecen más ingeniosas que sólidas. Por nuestra parte creemos que, descartadas las indudables imposturas que han afeado las tradiciones del Sacro Monte, queda en ellas mucho de verdadero y respetable». ¿Cuáles son las señales inequívocas a juicio de Simonet que hacen del Sacromonte impostado un verdadero centro de peregrinación, a pesar de las patrañas que lo han «afeado»? Contará: «Porque, además de los prodigios que acompañaron al descubrimiento de las grutas y cenizas en el siglo XVI, un documento no sospechoso, como de autor genuinamente arábigo, nos enseña que bajo la dominación sarracénica era celebrado aquel monte por señales prodigiosas y notables maravillas, entre ellas un humo misterioso que salía de cierta cueva inaccesible, situada en su ladera oriental, y que cambiaba de colores según el viento que soplaba» ${ }^{38}$. Se ve que Simonet doblega su método historicista, soportado en la prueba documental, ante la «piedad religiosa», ante el providencialismo al que atribuye la razón última de la historia.

Todos estos hechos milagrosos tienen de fondo, además, el gran acontecimiento mítico que desarrolla Simonet, o sea la supuesta batalla librada en Granada por el caudillo mozárabe 'Umar ibn Hafsūn contra 'Abd al-Rahmān II ${ }^{39}$. Describe Simonet el acontecimiento,

${ }^{37}$ Simonet, F. J., Cuadros históricos, 49.

38 Id., 50.

39 En la imaginación de Simonet 'Umar ibn Hafșūn era una suerte de resistente que había restaurado la pureza del cristianismo. Hasta Simonet Ibn Hafsūn no había atraído mucho la atención de los arabistas; a partir de él se convierte en un paladín de la fe, sobre el cual hace girar buena parte de su obra mozarabista (Acién Almansa, M., Entre el feudalismo y el Islam. 'Umar Ibn Hafșün en los historiadores, en las fuentes y en la historia, Jaén, 1994, 22-23). Además, según Simonet, tanto Casiri como Conde, Modesto Lafuente, Romey, Lafuente Alcántara y Pascual Madoz, equivocan sus pasos al situar la gesta de Ibn Hafșūn en el norte de la península; él reclama haber consultado las fuentes árabes directamente, las cuáles situarían unánimemente el episodio en la cora de Rayya, o sea de Málaga (Simonet, Fr. J., «Una expedición a las ruinas de Bobastro. Cartas dirigidas a don Aureliano Fernández Guerra», La Ciencia Cristiana, 1877, n. ${ }^{\circ}$ 4, 217-227, 309-322, 494-506; $\mathrm{n}^{\circ}{ }^{\circ}$, 136-147). La crítica actual, sin embargo, hace notar el carácter intencional de la invención de una genealogía mozárabe para Ibn Hafsūn, alejando al personaje de la heroicidad resistente que le otorga Simonet (Wasserstein, D. J., «Inventing Tradition and 
añadiéndole fuertes notas de imaginación histórica: «A principios del año 889 los árabes de Elvira, arrojados de sus alquerías, y aduares por los españoles, se acogieron y fortificaron en el antiguo castillo de Monte Sacro, desde donde infestaban las cercanías, capitaneados por Yahya Ben Socala, valeroso caballero de la tribu de Casi» ${ }^{40}$. Sobre la localización de la batalla, Simonet nos informa que Dozy piensa que fue en Montejícar, un lugar de la provincia de Granada, pero que «otros autores lo sitúan en el cerro del Sacro Monte, en el término de la misma ciudad». Por supuesto, él está entre esos «otros autores». De la virulencia de la batalla y el camino que abre hacia el martirio de los mozárabes vencidos, es fiel testimonio esta descripción: «Este caudillo (Sauar ben Hamdún) odiaba a los españoles como buen árabe, y los odiaba más terriblemente, porque ellos le habían matado a su hijo en la conquista del Monte Sacro. Deseoso, pues, de vengar á este hijo y á su compañero, Yahya, reunió á los árabes y marchando con ellos contra el mismo castillo del Monte Sacro, donde aún creía ver brotar la sangre de su hijo, lo tomó por asalto y pasó á cuchillo á seis mil españoles, y exterminando familias enteras de ellos, hasta el punto de que para muchos bienes faltaron herederos». Esta narración está más lograda desde el punto de vista literario y legendario que la que hiciera unos años antes el mismo Simonet en los artículos seminales en los que rescataba la figura de 'Umar ibn Ḥafsūn, donde se puede leer: «Llamado (Ibn Hafsún) por los de Elvira, que habían sacudido el yugo sultánico, pasó a aquella capital, estableció en ella una guarnición, y como al poco tiempo fuese expulsado por los realistas, volvió Omar y castigó duramente a sus adversarios, descabezando al gobernador nombrado por el Sultán, y reemplazándole por uno de su devoción. En vano Ibn Chudi caudillo del partido árabe, quiso dar ayuda al realista. Habiendo reunido en el castillo de Granada todas sus fuerzas y las de sus aliados, marchó contra Omar, viniendo con él a las manos en las inmediaciones de Elvira. El caudillo español desbarató a las huestes enemigas y le persiguió hasta los muros de Granada, haciendo en ella una matanza terrible»» ${ }^{41}$. Simonet nos ofrece, tanto en la versión de 1879 como en la Historia de los mozárabes, una batalla épica,

Constructing Identity: the Genealogy of 'Umar Ibn Hafsūn Between Christianity and Islam», Al-Qantara, XXIII, 2 (2002), 269-297).

40 Simonet, F. J., Historia de los mozárabes, III, 542.

41 Simonet, F. J., «Samuel ben Hafsún», La Ciencia Cristiana, XII (1879), 371. 
situada por él en el Sacromonte donde habrían muerto en martirio miles de mozárabes, sin más pruebas concluyentes que el deseo de que así hubiese transcurrido la jornada histórica en aquel lugar ${ }^{42}$. Las razones para el culto sacromontano están, pues, reforzadas por caminos distintos de los Libros Plúmbeos, pero ellas tienen en común con éstos que reposan sobre el martirio. Martirio y lugar quedan marcados y fijados mítica y ritualmente, con las supuestas cuevas donde habrían sido martirizados los cristianos y con la romería popular de primero de febrero a las mismas ${ }^{43}$.

Como sea que Simonet pretende adjudicar al «elemento indígena» todo rastro de brillantez cultural islámica, aplica ésta incluso al cautiverio. De la muralla del cerro de San Miguel, conocida como la «cer-

${ }^{42}$ Esta continuidad no consigue establecerla en Málaga, su patria natal, donde el culto a los mártires Ciriaco y Paula, martirizados entre finales del siglo III y principios del IV, no había dejado rastro durante la época árabe, dada la exigüidad de la comunidad mozárabe malagueña: «Los mozárabes malagueños fueron expulsados al África donde se extinguieron miserablemente. Desde entonces, si quedaron en Málaga algunos cristianos que conservaron la memoria y la tradición de los Santos Ciriaco y Paula debieron ser po$\cos (\ldots)$ No se sabe que éstos tuviesen ni comunicasen a los restauradores noticia alguna de nuestro Santos. En Málaga hemos tenido también la desgracia de que al tiempo de su conquista no se encontrasen ni aun huellas de las antiguas basílicas y templos cristianos» (Simonet, F. J., Los santos mártires Ciriaco y Paula, Patronos de Málaga, Málaga, 1865, 32-33). En la geografía del mito la continuidad es un elemento nodal.

${ }^{43}$ La vindicación del martirio es central en la obra e ideología de Simonet, así como en la producción del sujeto fóbico, ya que las mártires cordobesas en particular están sujetas a la idea de pureza sexual frente a la lubricidad representada por los musulmanes. E1 problema del martirio fue asimismo el punto de partida de la disidencia y la amistad con R. Dozy. Este autor, recordemos que catalogado de «protestante y racionalista» por Simonet, había reivindicado en el tomo segundo de la Historia de los musulmanes de Espa$\tilde{n} a$ a la cristiandad cordobesa bajo el poder califal, pero se había pronunciado en contra de aquella suerte de suicidio que en nombre del martirio promovía Eulogio de Córdoba, contraviniendo las disposiciones mayoritarias de la Iglesia mozárabe mucho más moderadas (Dozy, R. P., Historia de los musulmanes de España, Madrid, 1984, II, 119-ss.). Sobre esta trascendental cuestión para la comprensión de su evolución intelectual, Simonet dijo en el momento de la aparición de la obra de Dozy: «Lástima grande que nos causa que, extraviado por su criterio anticatólico, el escritor holandés haya manchado con apreciaciones violentas e injustas las bellas páginas en que ha trazado á grandes rasgos la historia de nuestros mozárabes. No acertando a comprender la abnegación y el sacrificio de este pueblo, animado por una idea más que humana, M. Dozy ha calificado de fanatismo la aspiración sublime al martirio inspirada por un ardentísimo espíritu católico» (Simonet, F. J., Recensión de «Historia de los musulmanes españoles», La Ciencia Cristia$n a(1879), 158)$. De esa crítica agridulce de Simonet a Dozy surgiría la amistad y el reconocimiento mutuo entre ambos, pero aquí nos interesa retener la importancia de la idea de martirio en el primero, hasta el punto de convertirla en uno de los elementos axiales de su obra. 
ca del Obispo don Gonzalo», dirá que fue construida por cristianos cautivos, según «varios letreros en lengua y escritura castellanas, descubiertos hace pocos años». También trae a colación la participación de prisioneros cristianos en la construcción de la Alhambra, una vez que un grupo de aquellos fue cautivado en la batalla de Algeciras ${ }^{44}$. Estos argumentos tienen como fin afirmar repetidamente la presencia cristiana en el Sacromonte, para nutrir el complejo de autoctonía de los granadinos, celosos de sus mitos de fundación ${ }^{45}$ y de la precedencia del cristianismo sobre el Islam.

Mas el martirio previo de los Varones Apostólicos debía medirse con otros mitos de fundación, y Simonet elude el asunto. Pretendiendo discernir lo verdadero de lo falso con el fin de validar sus argumentos de fondo y hacerlos verosímiles, Simonet sostiene que los Varones Apostólicos no sufrieron martirio en el Sacromonte, ya que cada uno de ellos se encuentra enterrado en las sedes apostólicas donde predicaran en vida: San Torcuato en Guadix, San Eufrasio en Andújar, San Tesifón en Berja, San Segundo en Ávila, San Indalecio en Almería, San Esicio en Cazorla. De lo que no le cabe duda es de que San Cecilio estuviese enterrado en Granada, incluso especula sobre en qué lugares de la ciudad pudo haberse asentado la comunidad mozárabe a la cual pertenecía el santo. El interés principal de Simonet es rehabilitar el horizonte mozárabe, al cual había dedicado la más importante y políticamente «violenta» de sus obras: La historia de los mozárabes de España ${ }^{46}$. Para ello empleará mecanismos de elisión y de mención que sitúan permanentemente al cristianismo sobre el Monte Sacro, y otros lugares marcados por la tradición.

En La historia de los mozárabes, el procedimiento para restablecer el mito de la cristianización primera de España retorna en toda su dimensión. Simonet, para hacernos visibles los sufrimientos de los cristianos bajo el Islam peninsular, nos remite a las contemporáneas comunidades cristianas del norte de África. Su operación, siguiendo

44 Simonet, F. J., Influencia del elemento indígena, 57.

45 González Alcantud, J. A., La ciudad vórtice. Lo local en tiempos de errancia, Barcelona, e.p. Llamamos complejo de autoctonía al complejo antropológico de pertenencia territorial e histórica de los sujetos, los linajes y las comunidades, tramado en las gestión cultural de los mitos de fundación, de origen, y en la legitimidad para la herencia y precedencia social y política.

46 Lo sostiene atinadamente Pedro Chalmeta en la introducción al libro de Manuela Manzanares de Cirre, Arabistas españoles del siglo XIX, Madrid, 1972, 14. 
al padre Flórez, consiste en situar en el primer lugar de la cristianización a Guadix, y al frente de los Varones Apostólicos a San Torcuato. Según Simonet, «allí habían predicado el Evangelio los Siete Varones Apostólicos, consagrados en Roma por los Apóstoles San Pedro y San Pablo, destinados por ellos para establecer en nuestra península la Iglesia y jerarquía eclesiástica, y venerados por nuestros mozárabes como los Padres de la fe; allí, después de un gran prodigio y en el famoso bautisterio erigido por la ilustre Luparia, se había cristianado todo el pueblo; allí, el Superior de los Siete Apostólicos, el glorioso San Torcuato, había establecido la primera sede episcopal que hubo en España, y allí había obtenido la palma del martirio; desde allí sus dignos compañeros se habían repartido por diversas regiones de la Bética y aun de la Lusitania» ${ }^{47}$. Gracias a esta actividad tan significada en la historia del cristianismo peninsular, Simonet recuerda que el oficio ritual mozárabe, que permaneció durante mucho tiempo en la Iglesia española, tuvo su origen en Guadix. Sostiene por demás que hubo un santuario entre Guadix la Vieja y Guadix, en un lugar llamado Face-Retama, donde se veneraban los restos de San Torcuato, hasta que en época de 'Abd al-Raḥmān I fueron trasladados al monasterio gallego de Celanova. En este lugar accitano se producían prodigios y milagros, de los que cuenta dos: a) la llamada «lumbre de San Torcuato», que aparecía sobre el santuario y las cuevas adyacentes al mismo; b) un olivo maravilloso, «plantado por el mismo santo apostólico en el atrio de aquel templo, que florecía todos los años en la víspera de su festividad, y a la mañana siguiente, el pueblo que concurría a la fiesta cogía gran copia de aceitunas ya maduras de las cuales sacaba un aceite que se empleaba, no solamente en alimentar las lámparas que ardían de continuo ante el altar y sepulcro de San Torcuato, sino además en remedio de muchos dolores». Simonet sale al paso de la cualquier probable acusación de superchería por la coexistencia del mismo milagro en Granada, en el cerro de San Miguel, y en otros lugares de España, justificándola por el «amor patrio» de quienes lo sostienen. Y que si en los autores árabes existen referencias al milagro éste suele coincidir siempre con el día de San Juan, el 24 de junio ${ }^{48}$; a diferencia del de Guadix que es el uno de mayo, festi-

47 Simonet, Historia de los mozárabes, I, 159.

48 En relación con las mascaradas de verano de compostura carnavalesca presentes en el mundo marroquí, véanse los trabajos clásicos: Westermarck, E., Survivances païen- 
vidad del Santo. Trae en su apoyo, siempre, el calendario de Recemundo, donde se habla expresamente de la fiesta de San Torcuato.

Por supuesto, Simonet no inventa los milagros atribuidos a San Torcuato y los Varones Apostólicos. Los extrae de tradiciones populares y árabes debidamente contrastadas, algunas de las cuales han sido en su momento señaladas por C. Jiménez Mata y J. Hernández Juberías ${ }^{49}$. El problema es que las cree literalmente, sin entrar en otras consideraciones; les concede a estas tradiciones verosimilitud histórica, como algunos autores de nuestra época aún hacen, dejando claro con ello la persistencia de la corriente simonetista, sobre todo en la escuela granadina. ¿En qué clave, si no, hemos de leer el artículo de Jiménez Mata, que comienza dando por supuesta la existencia, vida y obras de San Torcuato, para luego pasar a las fuentes árabes? ¿No es aquí la fe la que guía la mano del investigador, como en Simonet? Se ve que hay una confusión intencional entre las fuentes historiográficas y la verosimilitud histórica. La construcción de una nueva interpretación histórica exige, como venimos defendiendo desde el inicio de este artículo, nuevos instrumentos analíticos, sobre todo en relación con la ideación del mito.

En esa línea de confundir el testimonio documental con su realidad ocupa un lugar central en Simonet el santoral hispano-mozárabe de $\operatorname{Rabi}^{\mathrm{c}}$ b. Zayd, el último obispo conocido de Iliberis. Ibn Zayd habría vivido en la primera mitad del siglo $\mathrm{X}$, y era conocido en los ámbitos mozárabes con el nombre latino de Recemundo, que aquéllos acostumbraban a conservar. Simonet nos informa que tuvo una gran influencia en los califas 'Abd al-Raḥmān III y al-Ḥakam II. El primero le habría nombrado para una embajada ante el emperador Otón, en el año 955; embajada que aceptó a cambio de ser nombrado obispo de Iliberis. También nos informa de que más adelante llevó a cabo otro viaje a Constantinopla y Jerusalén. Entre sus actividades intelectuales cita Simonet que en «el año 941 compuso en lengua arábiga su célebre calendario astronómico agronómico que dedicó al mencionado

nes dans la civilisation mahométane. París, 1935, 178-216. Hammoudi, A., The Victim and Its Masks. An Essay on Sacrifice and Masquerade in the Maghreb, Chicago, 1993, 140-156.

49 Jiménez Mata, C., «A propósito del 'Âya' 'ib del olivo milagroso y su versión cristiana en el milagro de San Torcuato», Cuadernos de Historia del Islam, Serie Miscelánea, n. ${ }^{\circ}$ (1971), 97-108. Hernández Juberías, J., La península imaginaria. Mitos y leyendas sobre Al-Andalus, Madrid, 1996, 295-303. 
califa Alhacan II; mas procurando que fuese útil á los hombres de su religión, apuntó en él las principales festividades que celebraba á la sazón la Iglesia mozárabe española» ${ }^{50}$. Relata como prueba de su continuidad que Ibn Zayd incluyó en las conmemoraciones a los mártires «que habían sido sacrificados por mandato del gobierno musulmán». En cuanto a su amigo y protector ante Otón II, Luitprando, debe ser tenido en cuenta que en una lógica muy frecuente en la época le fue adjudicada una Crónica por el falsificador Román de la Higuera. Según esta Crónica, el sabio Luitprando habría visitado España, y en particular Toledo. Para Godoy Alcántara, lo que sorprende «es la activa y regular correspondencia que podía seguirse en el siglo $\mathrm{X}$ entre Granada y Fulda», si hubiese de creerse al cronicón. Destaca en el Cronicón de Luitprando una supuesta carta enviada por Tractemundo, obispo de Iliberis, a aquél, en la que «le cuenta la situación angustiosa en que viven los muzárabes granadinos, iglesia que tuvo por primer pastor á Cecilio, compañero de Santiago» ${ }^{51}$. Desde el inicio, pues, las figuras de Recemundo y Luitprando están mezcladas con los falsos cronicones, por lo que hay que rastrearlas con detalle. Contra esta mezcla ha actuado otra crítica más reciente, dentro del propio marco eclesial: «Los autores de los falsos cronicones, que tomaron a este diácono Ticinense por autor de sus desvaríos y sueños, le cambiaron el nombre de Eutrando, le hicieron diácono de Toledo y luego obispo de Cremona; y a nuestro obispo Recemundo le confundieron con Trectemundo» ${ }^{52}$.

Simonet, por ello, se ve en la obligación de demostrar la veracidad del calendario, y nos cuenta que aunque se había perdido el original árabe nos resta la copia latina que debió hacer Gerardo de Cremona en el siglo XIII. En 1838 un bibliófilo italiano llamado Guillermo Libri publicó el manuscrito en el tomo I de una Histoire des sciences mathematiques en Italie, publicada en París en aquellas fechas. Hizo Libri la transcripción del manuscrito, conservado en la «Biblioteca de París», según Simonet. La procedencia extranjera del manuscrito permitió a Simonet rechazar toda sospecha «de interpolación y false-

\footnotetext{
50 Simonet, F. J. (ed.), Santoral hispano-árabe escrito en 941 por Rabi ben Zaid, obispo de Iliberis, Madrid, 1871, 7-8.

${ }^{51}$ Godoy Alcántara, J., Historia crítica de los falsos cronicones, Madrid, 1981 180-181. Existe edición en Universidad de Granada con estudio preliminar de Ofelia Reyes.

${ }^{52}$ Fray Custodio de la Vega, España Sagrada, Madrid, 1961, LIII-LIV, 180.
} 
dad», amén del argumento, considerado por él definitivo, de los arcaísmos árabes contenidos en el documento. Finalmente el orientalista holandés Reinhart Dozy habría encontrado el manuscrito y transcrito del árabe, y le había transmitido a Simonet la noticia de los hallazgos en los siguientes términos: «Usted encontrará sin duda estas noticias muy curiosas y muy útiles. Flórez habría estado encantado puesto que le habrían podido servir para su magnífica «España Sagrada». En definitiva, este texto se presenta capital para demostrar la antigüedad de la presencia cristiana en la península, y más en particular en la Bética. Lo curioso del caso es que la demostración se fundamenta solamente en el siguiente párrafo: «Aprilis (...) XXVII. Et christiani nominant hanc diem usque ad septem, septem missos, Torquatum et socios ejus, et dicunt pisos septem nuncios». En nota a pie de página comenta Simonet los siguiente: «Las palabras missos y nuncios que se usan aquí, parecen traducción del árabe rosol, mensajeros, y equivalen á la de apostólicos con que se conoce generalmente a San Torcuato y sus seis compañeros». Aparece en la misma fecha del calendario un tal Bislo que traduce Simonet por San Basilio, mártir, sin que establezca ninguna relación directa con los Varones Apostólicos, excepto de participar todos ellos de la condición de mártires. Según Charles Pellat, la fiesta de este santo, sobre cuya identificación todos los exégetas del calendario están de acuerdo, está marcada en el calendario de la Iglesia griega como un martirilogio ${ }^{53}$.

Lo que nos oculta Simonet es que el propio Dozy había estado sujeto a críticas en relación con la identidad del obispo Recemundo y del autor del calendario mozárabe. Su crítico había sido el doctor Steinschneider, que había publicado las mismas en su obra Zeitschrift für Mathematik und Physik. Dozy en defensa propia alega, después de señalar la embajada de Recemundo ante Otón, la gran amistad que lo unió con Luitprando, durante su estancia en Frankfurt, y como éste le había dedicado su «Historia de los Emperadores y Reyes de su tiempo», después de que el andaluz lo hubiese animado a escribirla. Al final del artículo, y cuando Dozy parece haber disipado todas las dudas respecto a la personalidad de Recemundo, reintroduce la duda, resolviéndola de la siguiente manera: "Sólo queda por aclarar una dificultad, y es que Recemundo se llamaba "Rabi Ibn Zaid el obispo", y el autor del Liber Anoe es nombrado en la traducción latina "Harid filius Zeid epis-

${ }^{53}$ Pellat, Ch., Le calendrier de Cordoue, publié par R. Dozy, Leiden, 1961, 74. 
copus". Confieso que estas diferencias son lo que los ingleses llaman very puzzling, y hay que elegir una de las dos; pues, o esta circunstancia sola echa por tierra todo lo que hasta aquí hemos creído probar, o el traductor latino - que me parece ser Gerardo de Cremona, que vivió algunos siglos después del autor- se equivocó aquí y puso Harib por Rabi. Quizá encontraría la equivocación ya en el manuscrito árabe que usó». E invoca en este punto que ambos nombres se escriben en árabe con las mismas letras pero en distinto orden ${ }^{54}$. En todo caso Dozy nos ha sembrado de nuevo la duda sobre los azares de la escritura y los equívocos caminos que se abren cuando de breves líneas hemos de inferir un mito entero de fundación como el de Granada. Tal es la fragilidad de los mitos si hemos de buscar sus anclajes empíricos, sin someterlos al juicio crítico antropológico.

En ediciones posteriores la crítica filológica ha procurado resolver las dudas razonables en relación al calendario cordobés, introduciendo a nuestro juicio más criterios que desmontan la leyenda de los Varones Apostólicos. Charles Pellat, al revisar el texto de Dozy, encontró que pudieran ser dos textos: «Una combinación de dos obras de 'Arib b. Sa'd y de Recemundo; el primero debía ser un libro de $a n w \bar{a}$ ', puede ser que presentado bajo la forma de almanaque, el segundo un calendario sobre todo litúrgico; un autor posterior habría fundido los dos textos en uno solo» ${ }^{55}$. A todo esto habría que añadir las importantes diferencias entre el texto latino y el árabe ${ }^{56}$. Incluso la crítica eclesial manifiesta sus dudas razonables sobre la identidad de Recemundo obispo y $\operatorname{Rabi}^{\mathrm{c}}$ b. Zayd, autor del calendario mozárabe, considerando que las opiniones de Simonet están "anticuadas» ${ }^{57}$. Es más, Fray Custodio de la Vega se permite dudar de la localización del culto: «El uno de mayo se celebraba la festividad de los Siete Apostólicos o Siete Enviados, San Torcuato y sus compañeros, en el Monasterio Gerisset. El "locus eius Keburiene", es lugar totalmente desconocido, y que no creemos se refiera a Acci o Guadix» ${ }^{58}$. El problema, inferimos, más que filológico es mitológico y ritológico.

\footnotetext{
${ }^{54}$ Fray Custodio de la Vega, España Sagrada, Madrid, 1957, LVI, 196.

55 Pellat, Ch., Le calendrier, X.

56 Id. XV.

${ }^{57}$ Fray Custodio de la Vega, España Sagrada, LIII-LIV, 208-209.

58 Id., 218.
} 
En realidad todo el asunto del Sacromonte, tanto en Simonet como en la tradición general del mito, gira en torno al secreto. Podríamos decir con Georg Simmel que «la mentira no es más que una forma grosera, $\mathrm{y}$, en último término, contradictoria frecuentemente», en que se manifiesta la «cantidad de mutuo disimulo» necesario para la vida en sociedad. El secreto, la mentira, el disimulo, son todas ellas formas sociales, que no morales, de equilibrio social. «El secreto en este sentido - concluye Simmel-, el disimulo de ciertas realidades, conseguido por medios positivos o negativos, constituye una de las más grandes conquistas de la humanidad» ${ }^{59}$. Lo que ocurre es que Simonet, reconociendo de facto ese peso del secreto, se lo adjudica a los mozárabes, como tantas otras cosas, en lugar de a la taqiyya, u ocultamiento islámico, de los moriscos. Al igual que sustrae el milenarismo a los moriscos y lo desplaza a los mozárabes. El ocultamiento y el milenarismo caerán ahora del lado cristiano bajo el yugo islámico, pero la lógica es la misma que para los posteriores moriscos.

La presencia de Salomón en el discurso de los Libros Plúmbeos no puede dejar de recordarnos que éste era un recurso muy presente en la primitiva iglesia iliberritana, como demuestra el texto del obispo de Iliberis Gregorio intitulado «De proverbios Salomonis». En el mismo se sitúa a Salomón en el centro de las profecías bíblicas: «Cosa de admirar - escribe Gregorio- es que Salomón, el profeta más sabio de todos los hombres (....) cosa extraña es -repito- que un hombre tal ignorase y aun tenga por imposible conocer cuatro cosas (...) a saber: el rastro del águila que vuela, el paso de la serpiente sobre la piedra, el camino de la nave sobre el mar y la senda del varón en la mujer» ${ }^{60}$. La adivinación está presente en el corazón mismo de la Iglesia iliberritana. No puede así extrañar que el tema sea recuperado posteriormente para la elaboración del mito sacromontano, interpretándose presuntamente con imágenes alegóricas a través del propio obispo Gregorio, y poniéndose las bases para la recuperación del mito de la fundación primera de Granada por los cristianos. No podemos olvidar igualmente el papel de San Gregorio en la topografía imaginaria de Granada, cuyos templos tutelares se hallan en el Albayzín de Granada: San Grego-

59 Simmel, G., Sociología. Estudios sobre las formas de socialización, Madrid, 1986, I, 378.

60 Custodio de la Vega, España Sagrada, 1957, 38 y 57. 
rio alto y San Gregorio bajo. Los moriscos, por otra parte, habían incorporado el arte de la adivinación a sus formas de resistencia cultural. Los jofores o pronósticos, y los sellos de Salomón formaban parte de esa tradición resistente ${ }^{61}$. En la copia que de los Libros Plúmbeos dejó el morisco Alonso del Castillo, el sello de Salomón constituye el inicio de los mismos: «Sellos con que los sanctos Martyres Caecilio y Thesiphon dexaron sellados los libros que se hallaron en el Sacro Monte de Granada». Sus virtudes quedan relatadas así: "Preguntó nuestro superior Jacobo a la Santa Virgen María, y nosotros, acerca de ello por su mandato, escribimos esta historia. "¿Por qué se signa el traslado de la Verdad del Evangelio con este sello [se reproduce el sello de Salomón], y qué propiedad es la suya y del escrito que hay en él significativo?». La respuesta es: "Y oyóle su Señor y le dio un sello con un signo firmemente. Y diole sabiduría, y poder, y gobierno, y justicia, y benignidad; y con él sujetó al hombre, y el demonio, y el ave, y los vientos sujetándolos a su mandato» ${ }^{62}$. El sello se lo habría sustraído a Salomón su propia mujer. Se deriva de esta cesión con engaño, una desobediencia a Dios que le había dicho a Salomón que lo conservase siempre con él. Caratina, la mujer de Salomón, lo arroja al mar, y de éste se lo devuelven los pescadores, extrayéndolo de las entrañas de un pez capturado, después de su arrepentimiento por la desobediencia. La atracción de todo lo referente a Salomón es bien conocida, incluso en la arquitectura. Baste recordar el tratado «El templo de Salomón» de Juan Bautista de Villalpando. Las proporciones del supuesto templo de Salomón, casi siempre tomando la proporción hexagonal, muy similar a la estrella de seis puntas del Sello, procuraban dar la impresión de transmitir un secreto fundado en la sabiduría: «Un templo en el que, a modo de sumario, su mano omnipotente reunió todo lo más significativo, la misma mano todopoderosa que anteriormente había repartido lo creado, diseminándolo por todas las partes» ${ }^{63}$. La figura de Salomón sería vindicada también por los árabes, con la presencia de la

\footnotetext{
${ }^{61}$ Cardaillac-Hermosilla, Y., Les noms du Diable. Essai sur la magie, la religion et la vie des derniers musulmans d'Espagne: les Morisques, París, 2001. González Alcantud, Lo moro, 2002, 23-45.

${ }^{62}$ Hagerty, M. J., Los Libros Plúmbeos del Sacromonte, Madrid, 1980, 289.

63 Villalpando, J. B. de, El Templo de Salomón, Madrid, 1995 (1605), ed. de J. A Ramírez, y traducción del latín de J. L. Oliver Domingo, 12.
} 
mezquita de la Roca sobre el mismo emplazamiento del templo primitivo, hasta el punto de que solió confundirse durante mucho tiempo uno y otro ${ }^{64}$. El carácter secreto de todo lo referente al Sacromonte queda así remarcado, por vía de Salomón. El continuum del secreto irrumpe y crea la ilusión de continuidad y permanencia. El archivo secreto del Sacromonte, mantiene hasta el día de hoy esta lógica fuertemente enraizada en las mentalidades ultraconservadoras de las elites eclesiales y burguesas de Granada. Se sabe que el combate en torno al mito es sordo, perdurable y secreto.

Las posiciones del grupo arabista granadino nutrido por Simonet fueron las de la defensa ideológica a ultranza del discurso trazado por éste, y fundado en el par elisión y mención que conviniese en cada momento a la congruencia del mismo. La ideología de este grupo queda reflejada sobre todo en la revista La Estrella de Occidente, dirigida por el discípulo de Simonet, Antonio Almagro Cárdenas, que editada en árabe y castellano en Granada ${ }^{65}$, pretendía servir de órgano a la escuela arabista granadina. Con la misma prudencia y oportunidad ideológica interpreta de esta manera el espinoso asunto de San Cecilio La Estrella de Occidente: «Parece que Cecilio, así como su compañero Tesifón, eran de origen árabe. Quien, hasta ha llegado á suponer sabido el nombre que estos dos tuvieron antes de entrar en el seno de la Religión Católica. Pero en ningún documento reconocido como verídico por la Sede Romana consta tal cosa. Esta tradición, dado el caso de que nada tenga de verdad, es indudable que no deja de encerrar cierto poético encanto» ${ }^{66}$. Este "poético encanto» es el que encuentra el anónimo relator de la fiesta del uno de febrero, conmemoración de los supuestos martirios de San Cecilio y sus compañeros, día en el que una romería popular sube a la abadía del Sacromonte. El lugar, reconoce el relator, es poco frecuentado, si se exceptúa el día de la fiesta, en el que suben los romeros por «este camino, de suyo muy ameno por las hermosas y variadas vistas». El mito sacromontano permanecerá así, pues, gracias al aparato colegial estudiado por Manuel Barrios Aguilera, al igual que por la operación ideológica y académica del ambiente granadino ultra-

64 J. A. Ramírez, ibidem, IX-XII.

${ }^{65}$ López García, B., «"La Estrella de Occidente” (1879-1893) y el "Boletín de la Sociedad Unión Hispanomauritánica" (1894-1899): prensa granadina hispano-marroquí», Cuadernos de la Biblioteca Española de Tetuán, n. ${ }^{\circ}$ 23-24 (1981), 7-22.

${ }^{66}$ La Estrella de Occidente, año II, 1-febrero-1880. 
conservador que rodeaba a Simonet, que eludía y mencionaba, en función de la demostración de la existencia de un continuum histórico, secreto o patente, que contrapusiese en último término el monte sacromontano a la Alhambra. Para ello el proyecto de la abadía del Sacromonte tenía que alcanzar una universalidad similar a la del palacio nazarí, lo que no pudo alcanzar, bien por la crisis del siglo XVII ${ }^{67}$, entre otros factores, bien por las fallas mitográficas del proyecto iniciado con los Libros Plúmbeos.

La operación lógica que intenta llevar a cabo Simonet se inserta en la díada memoria/olvido y tiene como explicación de fondo la idea de complot, materializada en la leyenda negra urdida contra España, y en el secreto como continuum histórico. El secreto permitiría explicar la continuidad subterránea en la memoria de aparentes discontinuidades históricas. Simonet invierte el cuadro explicativo del orientalismo estetizante y científico, reintroduciendo por vía lógica el providencialismo. Aquí reside la naturaleza violenta de su discurso, que se sale de los caminos trillados hasta aquel entonces. Podemos concluir que la xenofobia de Simonet tiene un fundamento frio, ya que se enfrenta al racionalismo de su tiempo con las mismas armas, es decir, la prueba histórica, dirigiendo los argumentos hacia el reforzamiento del providencialismo y la centralidad de la verdad revelada en la Historia. Por eso el pulso de Simonet aún es de difícil resolución, y en mi opinión sólo podrá ser resuelto por una antropología naturalmente enemistada con la teología, como nuestro autor, argumentando a la inversa, en cierta forma preveía. Las pruebas en antropología no son solamente escriturales, reducibles al campo de la pura metáfora, sino de sentido, de ahí la fuerte oposición entre las lecturas textuales que de la historia hacen las hermeneúticas teológica y antropológica.

\section{RESUMEN}

El catedrático de árabe de la Universidad granadina, Francisco Javier Simonet, modifica su percepción del papel del Islam en la cultura española, otorgándole una importancia absoluta a los mozárabes, a raíz de su ida a aquella ciudad andaluza, y tener que medir sus argumentos con el mito de fundación de la mis-

${ }^{67}$ Bonet Correa, A., «Entre la superchería y la fe: el Sacromonte de Granada», en Andalucía monumental. Arquitectura y ciudad en el Renacimiento y el Barroco, Sevilla, 1986, 33-51. 
ma, que otorga a los Varones Apostólicos la precedencia fundacional, presidida por el martirio, frente a cualquier veleidad islamista. Simonet roza siempre el problema del Sacromonte, sin abordarlo directamente, procurando llevar a cabo un juego de elisión y mención que ponga a salvo su cristianismo providencialista, para el que reclama la verdad histórica y documental y dé salida a la maurofobia que lo posee. El Sacromonte se convierte en un hueco del sentido, siempre omnipresente, en Simonet, y al cual contribuye a sostener como mito.

\begin{abstract}
Francisco Javier Simonet, Professor of Arabic at the University of Granada modified his perceptions of the role of Islam in Spanish culture after moving to the Andalusian city and realising the need to match his arguments to the city's foundation myth by granting crucial importance to the Mozarabs. Simonet brushed constantly, by elision and mention, against the problem of the Sacromonte Lead Books without dealing with it directly, triying to maintain his Christian providentialism untouched, for which he claimed a basis in historical and documental truth, and at the same time release his Arabophobia. The Sacromonte is omnipresent in Simonet's work and he contributed to its survival as a myth.
\end{abstract}

